\title{
Key Vocabulary Learning Strategies in ESP And EGP Course Books
}

\author{
Zahra Akbari \\ Isfahan University of Medical Sciences, Isfahan, Iran \\ E-mail: akbari@mng.mui.ac.ir
}

Received: 17-06-2014

doi:10.7575/aiac.ijalel.v.4n.1p.1
Accepted: 08-08-2014

Published: 01-01-2015

URL: http://dx.doi.org/10.7575/aiac.ijalel.v.4n.1p.1

\begin{abstract}
An increasing body of research evidence is showing the advantages of using certain skills and behaviours called language learning strategies in general and vocabulary learning strategies (VLSs) in particular in the process of L2 acquisition. University students who require reading English texts in their fields of study have to expand their vocabulary knowledge in a much more efficient way than ordinary ESL/EFL learners. And ELT course books are a good place to incorporate learner training in this regard. The purpose of this study is to see how vocabulary learning strategies are treated in both the book designer's claims section and the exercises of English for Specific Purposes (ESP) course books for students of medicine and para-medicine on the one hand and English for General Purposes (EGP) course book used commonly by these students in Isfahan University of Medical Sciences, Isfahan, Iran on the other. In other words, the specified course books were analyzed based on the insights gained from VLS research to gauge the extent to which they have incorporated VLSs and training in using them. These books were published under the supervision of the center for studying and compiling university books in humanities (SAMT). Based on the review of the relevant literature, three key strategies were identified and an analytic framework was devised. The framework was then applied to the course books. It was found that the treatments in the specified course books were deemed unlikely to improve students' abilities with these important skills and strategies.
\end{abstract}

Keywords: Vocabulary Learning Strategies (VLSs), English for General Purposes (EGP), English for Specific Purposes (ESP), medical course books, paramedical course books, University students

\section{Introduction}

Vocabulary learning strategies (VLSs) play a key role in vocabulary learning as they help facilitate learners' vocabulary learning process. Research demonstrates that vocabulary learning strategies make learning more self-directed and transferrable to new situations but there is a need for training learners in the use of VLSs. Nation (2001) believes that since "learners differ greatly in the skill with which they use strategies, it is important to make training in strategy use a planned part of a vocabulary development program". As it is shown by Nation (2001), VLSs contribute to vocabulary size of the learners.

Among the four language skills, reading comprehension has always been the main concern of ESP instructors and ESP students (Sajadi \& Oghabi, 2011). The usual justification for this is that comprehension of an English text is an important tool for obtaining information about the latest technological and scientific developments in different fields of science (Jafari \& Shokrpour, 2012). The important factor underlying all attempts to teach academic English, however, is the fact that university students who require reading English texts in their fields of study have to expand their vocabulary knowledge in a much more efficient way than ordinary ESL/EFL learners (Cobb 2007 as cited in Behrouzi and Taherian, 2012).

As Oxford (2003) mentioned "Vocabulary is not explicitly taught in most language classes" (p. 9). ELT course books are the most convenient form of presenting materials (Tomlinson, 2001) and they are agenda for classroom practices; hence a good place to incorporate learner training (Bastanfar and Hashemi, 2010).

This study, as with the study carried out by Bastanfar (2010), attempts to apply criteria extracted from VLS research on local ELT materials to evaluate their treatment of VLS. The purpose is to analyze the specified course books based on the insights gained from VLS research to gauge the extent to which the sampled course books have incorporated VLS and training in using them. The main difference between the two studies is that, in Bastanfar and Hashemi's (2010) study, the course books analyzed and evaluated were course book series used to teach English in local General Education in Iran before EFL learners enter the university. They were evaluated based on Lake's (1997) evaluative framework of learner training, whereas in the present study, the course books were analyzed according to Nation (2001)'s taxonomy of VLSs and they were designed for EFL university students.

According to Schmitt (1997 as cited in Bastanfar and Hashemi, 2010; Ranalli, 2003), insights from research and scholarly discussion can be "filtering down" into recently published vocabulary-learning materials.(removed from here and added to the conclusion section) If one decides to include training in the use of VLSs in a curriculum, a taxonomy 
will be helpful. It can make clear which strategies are available for attention and thus allow for sufficient coverage while also permitting prioritization. A taxonomy can also allow one to find areas of overlap and redundancy to make training more efficient. A small number of taxonomies have been proposed for VLSs.

\section{Nation's taxonomy}

Among them, Nation's taxonomy (2001 as cited in Ranalli, 2003) makes clear the intentional character of vocabulary learning and increasingly bases his description on the qualities a strategy must have to warrant attention from a teacher. According to Nation, a strategy must:

- involve choice, that is, there are several strategies to choose from

- be complex, that is, there are several steps to learn

- require knowledge and benefit from training

- $\quad$ increase the efficiency of vocabulary learning and vocabulary use (p. 217).

Therefore, for the purposes of the present study, the taxonomy proposed by Nation (2001), as it was used by Ranalli (2003), was deemed most suitable. It divides strategies into three general classes: planning, sources and processes. The rationale behind this division is to separate the aspects of vocabulary knowledge (i.e., knowledge about words) from the sources of vocabulary knowledge and from learning processes. Although not comprehensive like Schmitt's, Nation's taxonomy has the advantage of being organized around less abstract categories making it more practical for analyzing a program of learner training. It also lends itself to a selection of a subset of "key" strategies upon which this study is based.

With this in mind, the following were chosen from Nation's taxonomy and designated as "key" strategies (Ranalli, 2003):

1. Repetition or review from the class of planning strategies.

2. Resource use in particular using a bilingual or monolingual dictionary from the class of strategies related to sources.

3. Recording or note-taking which is related to noticing in the class of process related strategies

\subsection{Planning repetition}

Hulstijn notes that "several decades of psycholinguistic research have made it clear that lexical information simply must be activated regularly not only for it to be retained in memory but also to ensure that it can be fluently accessed in real time communication (2001: 286)". Additionally, repetition is essential because there is so much to know about each word (e.g., syntactic, pragmatic, phonological, derivational, morphological, stylistic features, etc.) that "one meeting with it is not sufficient to gain this knowledge" (Nation, 2001: 75).

As mentioned by Ranalli (2003), a related strategy is retrieval which is what happens when a word-meaning pairing that has been noticed or comprehended later met again and the word form or meaning is produced, voluntarily or involuntarily, from memory. Retrieval is important for vocabulary learning because the act of retrieving a word strengthens the paths linking the form and meaning in memory, making subsequent retrievals easier (Baddeley, 1990). Learners should be made aware of the benefits of using retrieval when reviewing rather than simply rereading their notes (Nation, 2001).

\subsection{Recourse use: dictionaries}

Dictionaries are a primary source of lexical information for most learners and fulfill a variety of functions: decoding for comprehension, encoding for production and also for intentional learning of vocabulary (Scholfield, 1997). As stated in Ranalli (2003), studies show that many learners overuse them for comprehension purposes. Also, learners do not always make full use of the information they find in dictionary entries while decoding/encoding; in particular grammatical or other usage information provided by means of special codes.

\subsection{Recording}

Recording strategies such as keeping vocabulary notebooks and using word cards are one form of noticing. Noticing occurs when a learner focuses on a word or expression and recognizes it as something useful to learn. Vocabulary notebooks are probably the most common form of written student record but tend to vary greatly in format and quality of organization (McCarthy, 1990). Another potentially effective form of recording strategy is the use of word cards (Nation, 2001). The learner goes through the cards trying to retrieve the meaning, word form or other information from memory (Ranalli, 2003).

\section{Aims of the study}

The purpose of this study is to consider how VLSs are treated in English for Specific Purposes (ESP) and English for General purposes (EGP) course books in the fields of medicine and para-medicine.

1. Which of the three key VLSs are addressed in current ESP and EGP course books?

2. Do the course books facilitate successful adoption and continued use of any of the strategies by means of appropriate learner training? 


\section{Methodology}

It is a qualitative research in which the ESP course books for different fields of study and the EGP course book which is the same for different fields of study, including medicine and para-medicine, in Isfahan University of Medical Sciences, Isfahan, Iran were investigated based on the analytic framework devised by Nation (2001). Because both ESP and EGP course books in these fields were prepared and published under the supervision of the same center (i.e., SAMT), they had more or less the same format.

As with Ranalli (2003), the purpose of this study is to consider how vocabulary learning strategies are treated in coursebooks. The goal is to determine to what degree, if any, current coursebooks contribute to the development of learners' skilled use of vocabulary learning strategies. To answer these questions, the analytic framework which is a subset of 'key' strategies developed by Ranalli (2003) was used. It was on the basis of a review of the literature of vocabulary learning strategies, as well as general learning strategies and learner training. Unlike Ranalli who selected and analyzed three popular upper-level commercial course books according to this framework, this study analyzes EGP and ESP course books designed for medical and paramedical students in Isfahan University of Medical Sciences, Isfahan, Iran. And they were all published by the same publisher as university course books for students of medicine and paramedicine.

\section{Materials}

In EGP course book which is used by students in all fields of medicine and para-medicine, the book designer claims that the focus is on developing reading comprehension through sub-technical medical and paramedical texts together with comprehension exercises, teaching sub-technical vocabulary which is common in different fields of medicine and paramedicine, and gradually introducing some of the technical vocabulary specific to medicine and para-medicine in readings and translations.

The vocabulary learning activities in the book are divided into two: pre-reading activities and post-reading ones. In prereading activities, there are three consecutive parts: a list of new words with their pronunciations, few new words with their definitions, and few new words with their definitions and exemplifications. In post-reading activities, there are three kinds of vocabulary exercises: Filling in the blanks with an appropriate word either based on the part of speech of the given word or based on the meaning of a list of words given, matching the words in the two columns given, and finding the Persian equivalent for a list of technical words in medicine which appears after the translation exercise; most of these words are neither used in reading nor the translation. There is also a list of prefixes, roots and suffixes together with an example and/or its meaning, a list of symbols, and a list of medical abbreviations at the end of the book without any references made to them in any parts of the book.

In ESP course books, regardless of the students' field of study, the designer claims to help students learn their required specialized vocabulary as far as their academic studies are concerned. It is also noted that teaching technical terms requires the collaboration of the learners' content teachers in each field with the English teacher. It is necessary to mention that EGP course is held in the first semester in all fields and ESP course is held either in the second or third semester. It means that the learners have not yet become familiar with the concepts behind their technical terms.

The vocabulary learning activities in ESP books contain just post-reading activities almost similar to the ones in the EGP book. The main difference between the two is that different forms (i.e., parts of speech) of the given words to fill in each blank are given in the EGP book in a table while in ESP books, the learners are supposed to find the appropriate form of the given word themselves to fill in each blank in the sentence. On the other hand, in ESP books, filling-in-theblanks based on the meaning of the given word is in the form of multiple-choice question. There is no matching exercise in ESP books. However, there is a list of technical words in medicine which appears after the translation exercise and the learners are supposed to find their Persian equivalents; again most of these words are neither used in reading nor the translation. Similarly, there is a list of prefixes, roots and suffixes together with an example and/or meaning for each at the end of the book without any references made to them in any parts of the book.

\section{Results of analyzing VLSs in the course books}

\subsection{Planning Repetition}

Both EGP and ESP books include features obviously meant to provide further exposure to learned vocabulary. It appears that there is little likelihood of learners developing the helpful strategy of planning repetition on the basis of materials in this study. They definitely need consciousness-raising in this regard. Most learners are probably already aware of the benefits of repetition at some level, as evidenced by the universal practice of cramming before exams. What they need, however, is to understand how much they can gain from systematic repetition.

The course books analyzed here, by virtue of their lack of substantial explicit training in the strategy of repetition offer little assistance in this regard. The result is in line with that of Wan-a-rom (2012) who indicated that inadequate numbers of word repetition or recycling would not be good enough to prepare learners for academic and independent study at a university level and small proportions of word repetition could be evidence that incidental learning of most words is unlikely to occur.

\subsection{Dictionary Use}

Generally speaking, learners do not have to be prompted to use dictionaries; dictionary use is widespread. It is the quality of that use that is the problem. Learners have strong preferences for bilingual dictionaries regardless of the purpose to which these are put or the learner's proficiency level. Learners also tend to overuse dictionaries particularly 
for decoding during reading and underuse them for production or learning new vocabulary. Many learners fail to fully exploit the full range of information in dictionaries because of lack of familiarity with formats and codes.

EGP course book gives more attention to resource use than ESP course books, devoting some material to explicit learner training in the use of dictionaries (albeit only monolingual ones). First, learners are supplied with a table of phonetic symbols similar in format to Oxford Advanced Learner's Dictionary at the beginning of the book and then at the beginning of each lesson, the pronunciations of the new words are given. Second, the English synonyms of the new words are provided and some of the new words are also used in a sentence to help learners better understand and learn the meaning of the new words. Third, there are some fill-in-the-blank exercises which ask the learners to fill in the blanks with the appropriate part of speech of the words which are given in table. Students are also asked to fill in the blanks with the appropriate word chosen from a list.

There are also some matching exercises which ask the learners to match the words in one column with their equivalents in another column. Finally, at the end of each lesson, there are a number of new specialized words not previously seen in the reading texts or exercises which require the learners to find their Persian equivalents. All of these exercises require the learner to use a dictionary.

However, an important point is that learners tend to overuse bilingual dictionaries while reading. It was noted that learners need help to establish guidelines or principles about when to use dictionaries and when not to do so. The point is not to have learners discard bilingual dictionaries but to show them when and how to use them most effectively. Some additional general learner-training features are also needed to increase the chances of learners adopting and mastering dictionary skills.

In contrast, ESP course books are much more modest in the amount of attention it devotes to training in resource use. The activities which could be said to constitute implicit dictionary-skills training are as follows: students are asked to fill in the blanks in a number of sentences by choosing the appropriate word in multiple-choice exercises. Second, one word is given in bold face and students are required to fill in the blacks in some sentences with the appropriate form of the given word. Third, there is one cloze passage in each unit which the students are asked to fill in with the words given. Finally, there is a list of new specialized vocabulary not previously seen in the reading texts or exercises for which the students are asked to find Persian equivalents.

At the end of ESP books, there is a list of medical terminology which helps the learners develop their vocabulary knowledge through word analysis. By using a dictionary, students can find the meaning of the word and its constituent components.

What is the main problem is that dictionary skills are not introduced in ELT course books and the learners are expected to learn them by themselves. The learners, on the other hand, expect their teachers to teach them the dictionary skills. And the vicious circle continues throughout their education from guidance school to university. These skills are only taught in private English language institutes. It is one of the reasons why learners mostly refer to bilingual dictionaries to overcome their vocabulary learning problems.

\subsection{Recording}

Most learners already practice recording strategies in so far as they take some notes during class. However, the quality of those notes and how they are used vary greatly. Both EGP and ESP students ( $70 \%$ in each group) are used to writing the meaning of the new words at the top of it in the reading text. The new words are highlighted by coloring or underlining and at the end of the term they are put in a bilingual list to become prepared for the final exam. Few students (30\% in each group) number the new word and write its meaning in the margin of the related page. As it is found by McCrostie (2007), "learners have difficulty identifying high frequency words, and view all words they do not know as equally important." In other words, they look up every unfamiliar word in the dictionary on the one hand focus on word-for-word translation on the other.

As it is emphasized by Hall (2009) as well as Walters and Bozkurt (2009),"to truly master a word the amount of information a learner must know is astounding: First, they must know how the word is written, and pronounced as well as the meanings of its affixes. Next, they need to know the various forms and derivations of the word, the concept behind the word, and synonyms of the word. Lastly, they need to know the grammatical functions of the word or in what kind of patterns it occurs, collocations of the word, and constraints on the use of the word or in what contexts we can use the word and in what contexts we cannot use the word".

Furthermore, in line with Ahmad Azaman et al.' findings (2009), the learners did not favour note-taking strategies in a notebook though vocabulary notebooks have been recommended by many writers (Woolard, 2000). They think that it is a time-consuming activity.

For learners to use vocabulary notebooks effectively, we need to encourage them to record various pieces of information about a word, not just its meaning (Hall, 2009). The point is to work consciously on the development of a large corpus of automatic word knowledge. This may mean scheduling ten minutes at the end of an instructional period devoted to an on-going vocabulary homework, such as vocabulary notebooks. An important aspect of this gradual learning is that the instructor consciously cues reactivation of the vocabulary. That is, the teacher needs to provide initial encoding of new words and then subsequent retrieval experiences (Sokmen, 1997). Notes can also be taken to develop academic vocabulary by using thinking maps or using cognates to bridge the gap between Persian and English language (Kinsella, 2005). 
The findings of this study is consistent with Nakamura's results on (2002, pp.46-53 as cited in Hall, 2009) note taking strategies and L2 learning. Among the highlights in his review are the following:

1. Note-taking is one of the two most frequently used strategies in L2 learning (the other, repetition).

2. In Cohen (1990, p.128) the most popular pattern was to enter the material in a notebook in the same order it was presented in class and Schmitt (1997) reports that "taking notes in class" is one of the most used strategies by EFL learners.

In line with Ranalli' findings (2003), there is a crucial lack of specific guidance for how to keep and exploit lexical records as well as tasks or other material to fulfill most of the general learning-training principles. It appears unlikely that students' use of recording strategies will be much altered on the basis of training they receive in EGP and ESP books.

\section{Discussion}

The way vocabulary activities are presented in EGP and ESP course books reinforces the learners' preference for rote learning as a traditional habit mainly attributed to their "educational background" and "failure to try out the best strategies" (Li, 2004; Hayati Samian and Tavakoli, 2012). As it is mentioned by Hayati Samian and Tavakoli (2012: 629),"the educational system in Iran and our course books guides the learners toward rote learning strategies. Moreover, Iranian learners show reluctance to trying new strategies and strategy training." It is mainly because they are not made familiar with different vocabulary learning strategies during their education from guidance school where English is introduced for the first time in general education to university where the course books still suffer from a widespread lack of attention to VLS presentation and learner training.

The findings of this study are very much in line with what Sinclair and Ellis (1992) as well as Ranalli (2003) noted as the shortcomings in the course books they analyzed. Assuming no supplementary training or materials are provided, use of these course books will yield variable and generally inadequate development of the three key strategies. In general, the task of developing skillful use of these strategies appears to be very much left to teachers or to learners themselves. If this is so, we are probably safe in assuming that many learners using these books will continue to go about their language learning handicapped by the lack of a sufficient repertoire of strategic tools for lexical development.

As it is stated by Gu (2003 as cited in Doczi, 2011), most of the students are ineffective vocabulary learners and have a limited understanding of what it means to 'know a word'. The goal of strategy training is to promote learner autonomy, i.e., get them to practice effective strategies, and take charge of their own learning (Rezvani Kalajahi and Pourshahian, 2012).

In order to provide the learners with the relevant instruction, teachers themselves should have a good command of strategies; thus, they should be instructed about strategy use teaching. The strategy instruction can be incorporated into the methodology courses given at the teacher education programs (Heidari, Karimi, and Imami; 2012).

The results are also consistent with those presented by Bastanfar and Hashemi (2010) on general education English course books: "The range of VLS which are presented, of course implicitly, is so limited that important strategies such as resource use and note-taking are not dealt with. There is no extended and long-term plan for generalizable and personalized vocabulary construction and strategy instruction; instead single and isolated activities are used" (p.163). Thus, inadequate treatment of VLSs is a general deficiency which most course books in general education system and university education system suffer from. Therefore, It is useful to incorporate useful vocabulary learning strategies in academic textbooks to help learners build up their vocabulary (Hamzeh, Kafipour, and Abdullah; 2009).

Reading comprehension and translation are the main skills focused in EGP and ESP courses as they are required by the learners both during their education and in their professional settings in future. Since language learning strategy instruction has positive effects on development of skills and components of language such as reading comprehension (Philp and Hua, 2006; Nambiar-Gopal, 2002; and Wu, 2005), incorporating vocabulary learning strategies in academic English course books can not only enable the vocabulary achievement and reading comprehension but also improve the leaners' confidence, decrease their anxiety, increase their motivation and interest and consequently, make them independent and autonomous in learning (Heidari, Karimi, and Imami; 2012).

\section{Conclusion}

In recent years, in line with a more learner-focused view of education, there has been increasing interest in language learners themselves and how they approach the task of learning. This learner-centered focus has two significant effects on classroom teaching and curriculum planning. First, in response to the recognition that learners are individuals with unique learning needs, teachers and course designers are aiming to design courses and classroom materials with a specific group of learners in mind.

A second effect of learner-centered education is the provision for learners to work independently, both in and out of classroom, allowing learners more control over what is learned, when and where that learning takes place (Nation, 2002). In order to develop an ever-improving capability to learn and use English effectively, learners need to develop appropriate strategies for lifelong learning (Ebrahimi Kavari, 2014).

In addition, the classroom is unlikely to be able to provide all the lexis a learner will need and the lexical needs are largely unique to the individual based in part on personal preference, professional and academic particularities, etc. (Ranalli, 2003). 
Considering these factors, it can be argued that syllabus designers, course book writers and classroom teachers are not only justified but even duty-bound to devote some attention to VLSs. The primary aim of teaching must be to raise the students' awareness of their increasing responsibility for and power over their own learning (Woolard, 2000).

Assuming that one accepts the argument that training in VLSs is warranted, and further that academic course books are an appropriate place for such training to be based, it is obvious that there is great scope for treatment of key strategies in course books. First, the need for writers to become better acquainted with the research regarding VLSs so as to ensure that their advice is appropriate and well-founded. According to Schmitt (1997 as cited in Bastanfar and Hashemi, 2010; Ranalli, 2003), insights from research and scholarly discussion can be "filtering down" into recently published vocabulary-learning materials.

Also, there is a great need for a fuller understanding of the processes of learner training and to value this understanding reflected in the tasks and guidance provided to students and teachers. A common theme in the materials-development literature is the lack of space and the strict specifications and formats governmental publishers have for academic course books.

When teaching materials fall short, teachers should be able to fill in the gaps. VLS development and principled learner training should be incorporated into teacher training curricula with the goal that teachers become discriminating users of materials, able to identify omissions and weaknesses and to supplement accordingly.

\section{References}

Mokhtar, A. A., Rawian, R. M., Yahaya, M. F., Abdullah, A., \& Mohamed, A. R. (2009). Vocabulary learning strategies of adult ESL learners. The English Teacher, 38, 133-145.

Baddeley, A. (1990). Human Memory: theory and practice. London: Lawrence Erlbaum Associates.

Bastanfar, A. and Hashemi, T. (2010). Vocabulary learning strategies and ELT materials: A study of the extent to which VLS research informs local course books in Iran. International Education Studies, 3, 158-166.

Behrouzi, P. and Taherian, A. (2012). The effect of learning academic word list on reading comprehension of Iranian undergraduate students. ELT Voices- India, 2(6), 39-55.

Cobb, T. (2007). Computing the vocabulary demand of L2 reading. Language Learning and Technology, 11(3), 38 -64.

Cohen, A. D. (1990). Language learning: Insights for learners, instructors, and researchers. NY: Newbury House/HarperCollins.

Dóczi, B. (2011). Comparing the vocabulary learning strategies of high school and university students: A pilot study. WoPaLP , 5, 138-158.

Ebrahimi Kavari, K. (2014). Teaching vocabulary in ESP contexts through vocabulary learning strategies instruction. Asian Journal of Research in Social Sciences and Humanities, 4 (2), 247-256.

$\mathrm{Gu}, \mathrm{Y}$. (2003). Fine brush and freehand: The vocabulary learning art of two successful Chinese EFL learners. TESOL Quarterly, 37, 73-104.

Hall, J.M. (2009). Vocabulary notebooks: A presentation at the 32nd annual All Japan English Education Conference retrieved from www.englisheducation.iwate-u.ac.jp/...vnote.htm

Hamzah, M. S. G., Kafipour, R., \& Abdullah, S. K. (2009). Vocabulary learning strategies of Iranian undergraduate EFL students and its relation to their vocabulary size. European Journal of Social Sciences, 11(1), 39-50.

Hayati Samian, S. and Tavakoli, M. (2012). The relationship between Iranian EFL learners' rote learning strategy use and their level of proficiency. Journal of Language Teaching and Research, 3(4), 625-631.

Heidari, F. L., Karimi, F., \& Imani, A. (2012). Vocabulary Learning Strategy Instruction: It's Impact on English for Specific Purpose Vocabulary Achievement and Reading Comprehension. Middle-East Journal of Scientific Research, 12(11), 1488-1496.

Hulstijn, J. (2001). Intentional and incidental second language vocabulary learning: A reappraisal of elaboration, rehearsal and automaticity. In P. Robinson (Ed.), Cognition and second language acquisition instruction (pp. 258-286). Cambridge: Cambridge University Press.

Jafari, S. M. and Shokrpour, N . (2012). The reading strategies used by Iranian ESP students to comprehend authentic expository texts in English. International Journal of Applied Linguistics and English Literature, 1(4), 102-113.

Kinsella, K. (2005). Teaching academic vocabulary. RCE. RESOURCE. A SCOE Publication.

Li, X.P. (2004). An analysis of Chinese EFL learner's beliefs about the role of rote-learning in vocabulary learning strategies. Retrieved July 14, 2008, from http://www.asian -efl-journal.com/xiuping_11-5_thesis.pdf.

McCrostie, J. (2007). Examining learner vocabulary notebooks. ELT Journal, 61 (3), 246-255.

Nakamura, T. (2002). Vocabulary Learning Strategies: The Case of Japanese Learners of English. Kyoto: Koyo Shobo.

Nambiar-Gopal, R. (2002). Empowering learners to become effective readers. IPBA International Conference 2002 Proceedings. Retrieved November 7, 2010 from http://apps. emoe. gov. my/ ipba/ rdipba/cd1/article128. 
Nation, I. S. P. (2001). Learning vocabulary in another language. Cambridge: Cambridge University Press.

Oxford, R. (2003). Toward a more systematic model Pf L2 learner autonomy. In Palfreyman, P., and Smith, R. (Eds.), Learner autonomy across cultures: language education perspectives (pp. 75-91). Great Britain: Palgrave Macmillan.

Philip, B. and T. Hua, (2006). Metacognitive strategy instruction (MSI) for reading: Co-regulation of cognition. Journal E-Bangi, 1(1), 1-27. Retrieved April 2, 2008 from http://eprints.ukm.my/26/1/tankimhua -edited.pdf.

Ranalli, J. M. (2003). The treatment of key vocabulary learning strategies in current ELT course books: repetition, resource use, recording. Unpublished MA thesis. University of Birmingham. [online] available:www.cels.bham.ac.uk/resources/essays/RanalliDiss.pdf (October 21, 2008)

Rezvani Kalajahi, S. A. and Pourshahian, B. (2012). Vocabulary learning strategies and vocabulary size of ELT students at EMU in northern Cyprus. English Language Teaching, 5 (4), 138-149.

Sajadi, F. and Oghabi, M. (2011). Relation between instructors' objective needs and students' subjective needs: the case of Iranian post graduate students. The Asian ESP Journal, 7(4), 123-152.

Scholfield, P. (1997). Vocabulary reference works in foreign language learning. In N. Schmitt and M. McCarthy (Eds.),Vocabulary: Description, acquisition and pedagogy (pp. 237-257). Cambridge: Cambridge University Press.

Schmitt, N. (1997). Vocabulary learning strategies. In N. Schmitt \& McCarthy, M. (Eds.) Vocabulary: Description, acquisition, and pedagogy (pp. 199 - 227). Cambridge: Cambridge University Press.

Sinclair, B. and Ellis, G. (1992). Survey: learner training in EFL course books. ELT Journal, 46 (2), 209-244.

Sokmen, A. (1997). Current trends in teaching second language vocabulary. In N. Schmitt and M. McCarthy (Eds.), Vocabulary: Description, acquisition and pedagogy (pp.237-58). Cambridge: Cambridge University Press.

Tomlinson, B. (2001). Materials development.In R. Carter \& D. Nunan (Eds.), The Cambridge guide to teaching English to speakers of other languages. Cambridge: Cambridge University Press.

Walters, J. D. and Bozkurt, N. (2009). The effect of keeping vocabulary notebooks on vocabulary acquisition. Language Teaching Research, 13(4), pp. 403-423.

Wan-a-rom, U. (2012). Lexical evaluation of teacher-made course books: Thai case studies of foundation English courses at tertiary level. English Language Teaching, 5(8), 146-156.

Woolard, G. (2000). Collocation: encouraging learner independence. In M. Lewis (ed.). Teaching Collocation: Further developments in the lexical approach. Hove, England: Language Teaching Publications, 28-46.

$\mathrm{Wu}, \mathrm{W} . \mathrm{S}$. (2005). Use and helpfulness rankings of vocabulary language strategies employed by EFL learners in Taiwan. Journal of Humanities and Social Sciences, 1(2), 7-13. 